\title{
ESF-EuroClimate: Radiocarbon and ice-core chronologies during glacial and deglacial times
}

\section{Heidelberg, Germany, 5-7 March 2007}

Bernd Kromer ${ }^{1}$, Barbara Wohlfarth ${ }^{2}$ and Daniela Turk ${ }^{3}$

${ }^{1}$ Heidelberg Academy of Sciences, Germany; bernd.kromer@iup.uni-heidelberg.de

${ }^{2}$ Stockholm University, Sweden

'European Science Foundation, Strasbourg, France

EuroCLIMATE is a European Collaborative Research Programme (EUROCORES) that coordinates and promotes research on climate variability and the past, present and future dynamics of the carbon cycle (www.esf.org/euroclimate). A key component of the program is an accurate time scale of climate archives to infer spatial patterns and rate of climate change. EuroClimate projects provide, and profit from, advances in dating techniques for the glacial and deglacial interval, as discussed at this workshop co-sponsored by PAGES.

M. Friedrich, F. Kaiser and F. Guibal/C. Mirramont presented late glacial tree-ring chronologies. Beyond the absolutely dated part, starting at $12,593 \mathrm{BP}$, several floating pine chronologies were constructed, and are currently being cross-matched into a Bølling/Allerød sequence, covering the ${ }^{14} \mathrm{C}$ age range of 12.5 to $10.6{ }^{14} \mathrm{C}$ kyr BP. S. Talamo and B. Kromer presented the ${ }^{14} \mathrm{C}$ sequences obtained from the floating sections and compared them to the marine based ${ }^{14} \mathrm{C}$ calibration data set IntCal04. The tree-ring based data set can be matched to IntCal04 for most of the Allerød interval but clear discrepancies are apparent for three centuries around the onset of theYounger Dryas (YD). One explanation involves an increased marine reservoir age in the ${ }^{14} \mathrm{C}$ data set from Cariaco Basin. R. Muscheler suggested an alternative solution, based on a link of ${ }^{10} \mathrm{Be}$ in Greenland ice cores to ${ }^{14} \mathrm{C}$ anomalies in the tree ring sequence, which would imply timescale differences between IntCal04 and the tree ring/ice core scales around the onset of the Younger Dryas. A. Hogg and C. Turney presented fascinating prospects for tree ring based ${ }^{14} \mathrm{C}$ sequences from millennialong Kauri sections, ${ }^{14} \mathrm{C}$ dated between 25 and $45{ }^{14} \mathrm{C}$ kyr BP.

L. Edwards demonstrated recent improvements in U/Th dating and new high-resolution ${ }^{18} \mathrm{O}$ series from Dongge and Hulu cave stalagmites. K. Hughen presented the revision of the Cariaco ${ }^{14} \mathrm{C}$ calibration data set, now anchored to the U/Th-dated Hulu cave record, back to 50 cal kyr BP. Consistent ${ }^{14} \mathrm{C}$ calibration back to at least $45 \mathrm{cal}$ kyr BP, based on the revised data set and new coral data, now appears feasible. ${ }^{14} \mathrm{C}$ calibration procedures

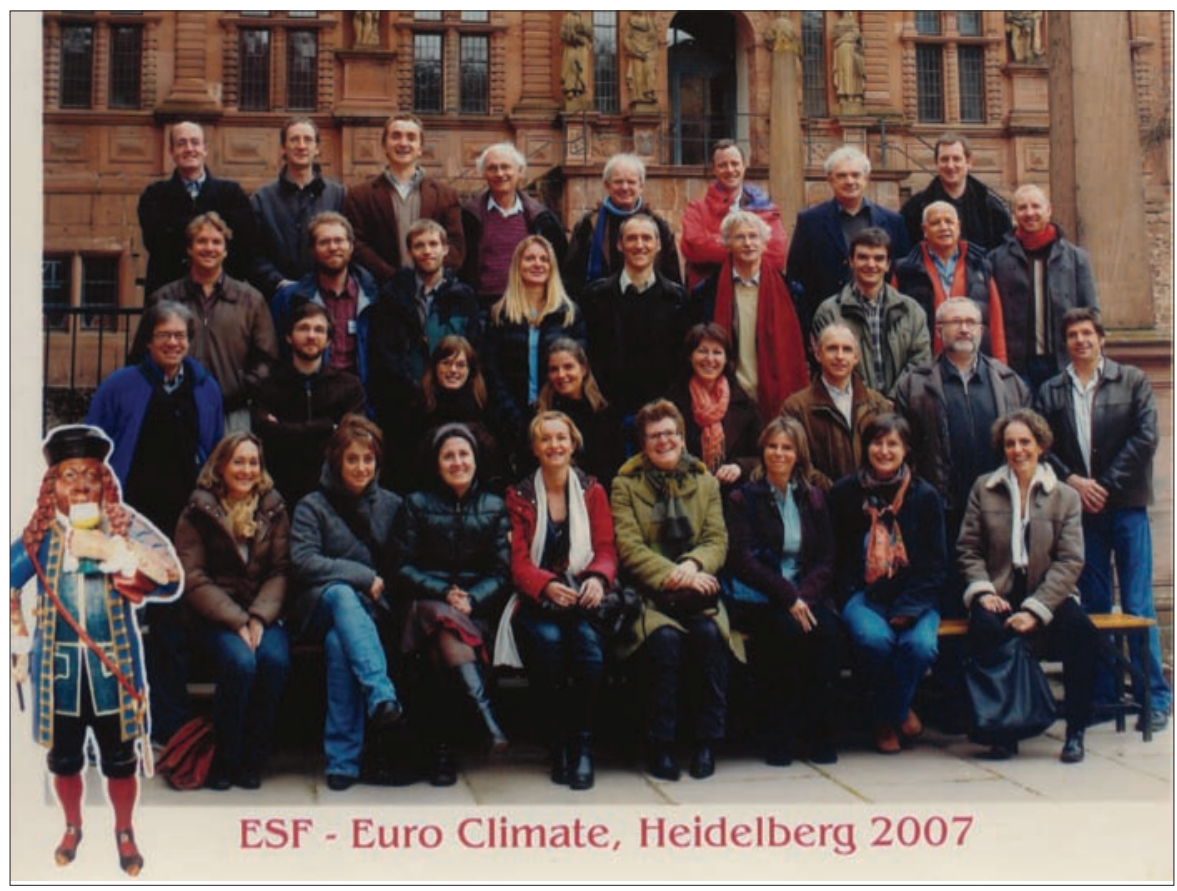

Figure 1: Participants of the EuroClimate workshop

and the importance of high-resolution sequences were demonstrated by $M$. Blaaw, using sections of the RESOLuTION project (PAGES News 2007, 1)-a EuroCLIMATE project presented by B. Wohlfarth, M. F. Sánchez-Goñi and J.A.A. Boos. The new Greenland ice core timescale GICC05, shown to have profited greatly from the progress in multi-tracer, continuous flow analysis, was presented by A. Svensson and S. Johnsen. F. Preusser demonstrated the state of the art on OSL dating of lacustrine sediments, using two cores from Les Echets, France.

J. Beer addressed the question of common, production-induced signals in the fluctuations of ${ }^{14} \mathrm{C}$ and ${ }^{10} \mathrm{Be}$ recordsas opposed to climate and carbon system effects-and presented new evidence for a dominant production signal. I. Hajdas discussed ${ }^{14} \mathrm{C}$ anomalies in several data sets during Heinrich event 4. C. Spötl and A. Mangini presented complex response patterns of ${ }^{18} \mathrm{O}$ in speleothems in the Austrian Alps, as compared to northern hemisphere climate proxies. A. Brauer and U. von Grafenstein presented new advances in chronology and stratigraphy of sediment records from five European lakes, based on detailed micro-facies and $\delta^{18} \mathrm{O}$ analyses. D. Verschuren showed first results of the CHALLACEA project, which aims to reconstruct climate variability, from preLGM to present, in equatorial East Africa using a finely laminated sediment record from Lake Challa, Mt. Kilimanjaro.

Participants noted the strong synergies offered by the ESF EuroCores concept-and exemplified during the workshop- resulting from collaboration between 'producers' and 'users' of chronologies. Tree-ring based ${ }^{14} \mathrm{C}$ calibration of terrestrial sequences was agreed to be of prime importance. The Europe-wide aim to locate glacial and late glacial subfossil wood and the initiative to extend the Kauri database was, therefore, considered essential. The current update of the radiocarbon calibration data set IntCal04 was welcomed. New climate proxy records, especially from well-dated speleothems, will be an important addition to the coverage of climate records, and will fill gaps at low latitudes. 